\title{
VIEWS OF PARENTS WITH TYPICAL EDUCATION CHILDREN ABOUT INCLUSION OF CHILDREN WITH AUTISM IN GENERAL SCHOOL
}

\author{
Zaragas Harilaos ${ }^{1}$, \\ Sarris Dimitrios, \\ Exarchou Evangelia ${ }^{3 i}$, \\ Papadimitropoulou Panagoula, \\ Exarchos Konstantinos ${ }^{5}$, \\ Maglara Vasiliki ${ }^{6}$ \\ ${ }^{1}$ Assistant Professor, \\ Department of Preschool Education, \\ University of Ioannina, \\ Epirus, Greece \\ ${ }^{2}$ Assistant Professor of Special Education, \\ Director of Laboratory Hall of Special and Therapeutic Education, \\ Department of Preschool Education, University of Ioannina, \\ Epirus, Greece \\ 3Postgraduate Student, Department of Preschool Education, \\ Laboratory researcher of Specialty and Therapeutic Treatment, \\ University of Ioannina, \\ Epirus, Greece \\ ${ }^{4}$ Laboratory researcher of Specialty and Therapeutic Treatment, \\ University of Ioannina, \\ Epirus, Greece \\ 5Primary schoolteacher, \\ Epirus, Greece \\ ${ }^{6}$ Kindergarten teacher, \\ Epirus Greece
}

\begin{abstract}
:
In recent decades, the debate over the successful implementation of accession policy has been growing. Teachers and parents are called upon to face a new reality. This paper discusses the views of parents with children in typical education regarding the inclusion of children with Autism Spectrum Disorder in the general school. Individual goals are to investigate parents' knowledge of ASD and factors that may affect parents' perceptions of inclusion. The research sample consists of 159 parents with children of typical education attending primary education (primary schools). Data were collected using a
\end{abstract}

i Correspondence: email evanexar95@gmail.com 
questionnaire with 10 questions on a Likert scale. The results showed that parents as a whole are positive about inclusion, but their views vary depending on some demographic features such as age, marital status, economic level and educational level.

Keywords: autism spectrum disorder, inclusion, parents, general school

\section{Introduction}

In recent decades there has been a large increase in the inclusion of people with special educational needs. In Greece, Legislation (Law 3699) in 2008 on special education and training considers children with autism and other pervasive developmental disorders as students with disabilities and special educational needs (Syriopoulou-Dellis \& Kassimos, 2013), which allows them participation in inclusion programs.

The purpose of the present study is to find out parents' knowledge of ASD (Autistic Spectrum Disorder) and factors that may affect parents' perceptions of inclusion.

\section{Literature Review}

\subsection{Autism Spectrum Disorder (ASD)}

Autism is a disorder that consists a serious form of psychopathology that usually occurs before the child reaches the age of three (Kakouros \& Maniadaki, 2006). It belongs to the broader category of Diffuse Developmental Disorders, which are chronic and require early, intensive, and therapeutic treatment (Grandin \& Scariano, 1995). It is determined based on the behavioral and developmental characteristics of the individual and is characterized by qualitative deficits in social interaction and communication as well as by limited, repetitive and stereotypical patterns of behavior (Heward, 2011). Regarding the etiology of the disorder, in recent decades there have been views on organic etiology (Grabrucker, 2013, Pardo et al. 2005), existence of heredity, as siblings of children with autism are 3\% more likely to develop the disorder themselves (Kalyva, 2005), while finally, the multifactorial nature of autism is supported (Lampi et al., 2012), highlighting the role of environmental factors such as the exposure to chemicals (lead, etc.) (Landrigan, 2010), the eating habits of mother during pregnancy until preterm birth, the maternal age at conception, the maternal smoking during pregnancy, and possibly specific vaccines given to children.

\subsection{Inclusion}

The education of students with ASD is a widespread issue, as it is of great concern to the educational community, the families of children in the autism spectrum, but also and many scientists involved in ASD (Mavropoulou, 2008). 
In 2008, a law was passed in Greece (3699) on special education and training, according to which children with autism and other pervasive developmental disorders are considered students with disabilities and special educational needs (SyriopoulouDelli \& Kasimos, 2013). This recognition has allowed the students of this group to participate in inclusion programs with all the benefits it entails.

An important factor in the education of children with and without special educational needs in educational inclusion programs is the active participation of the family. The involvement of the family is considered important for the education of children of all ages but more for the success of young children who participate in educational inclusion programs (Xu \& Filler, 2008). Several studies also (Stoiber et al, 1998, Tafa Manolitsis, 2003) show that parents of typically developing children appear to be more positive than negative about having a mixed class of children with learning and other disabilities with children becoming more sensitive and understand more the needs of their fellow human beings.

\subsection{Purpose of the Study}

The aim of the research is to investigate the views of parents with children of typical education regarding the educational inclusion of students with ASD in their children's school. Individual goals are the knowledge of parents of children with typical education towards ASD and the investigation of factors that may affect the perceptions of parents.

\subsection{Significance of the Study}

In global research, many studies have been conducted (Gallagher et al, 2000, Stoiber et al, 1998), Yasutake \& Lerner, 1997) regarding the views of parents with children in typical education, showing positive views of parents about inclusion. In Greece, research by Tafa Manolitsis (2003), show that the parents of typically developing children appear to be more positive than negative about the existence of a mixed class of children with learning disabilities and without any disabilities. Given the limited number of studies in our country on the views of parents of children in typical education towards inclusion, it is considered very important to contribute with this research in the scientific knowledge we have about the perceptions of parents with children of typical education towards children with Autism Spectrum Disorder.

\section{Methodology}

\subsection{Research questions}

To achieve the goal of the present research, the following research questions were asked:

- What are the views of parents of typical developmental students towards the inclusion of children with ASD in the general school?

- Does gender affect parents' views toward inclusion?

- Does age affect parents' attitudes views toward inclusion? 
- Does the educational level influence the parents' views towards inclusion?

- Does the professional level influence parents' views towards inclusion?

- Does the place of residence affect the parents' views towards inclusion?

- Does the marital status influence parents' views toward inclusion?

\subsection{Material}

A questionnaire was used for the purpose of the research. The questionnaire was aimed at investigating parents' perceptions of the inclusion of children in the autism spectrum in the general classroom. The tool is an adaptation of some questions in Greek of the CoTeacher Relationship Scale (McCormick \& Noonan, 2003) and Perceptions of CoTeaching Survey (Austin, 2001), which was done by Rousou Panagiota, SyriopoulouDelli Christina and Agaliotis Ioannis. It consists of two parts, with the first containing 6 questions concerning the demographic data of the participants and the second part 10 closed-ended questions for the educational inclusion of children with ASD. The answers are measured with the 5-point Likert scale from $1=$ completely disagree and $5=$ completely agree.

\subsection{Procedure}

The questionnaire given to the participants was anonymous in order to ensure the anonymity and protection of the participants in this research. Questionnaires were granted and supplemented individually, and parent participation was optional. The purpose of the study was explained to the participants and the researchers provided them with a questionnaire file, which they returned to the researchers completed.

\subsection{Sample}

The sample of the present study consists of 159 parents of children of typical education (104 women and 55 men) aged 21-59 years who had at least one child attending a primary school class. The sample was selected using the random sampling method. Not all participants had a child with ASD in the classroom of their child. Table 1 shows the demographic characteristics of the sample.

Table 1: Features of the sample $(f=159.100 \%)$

\begin{tabular}{llcc}
\hline Independent Variables & Teams & $\mathbf{f}$ & $\mathbf{\%}$ \\
\hline \multirow{3}{*}{ Sex } & Male & 55 & 34,6 \\
& Female & 104 & 65,4 \\
\cline { 2 - 4 } & Total & 159 & 100 \\
\hline \multirow{4}{*}{ Age } & $21-25$ years old & 11 & 6,9 \\
& $26-35$ years old & 58 & 36,5 \\
& $36-45$ years old & 72 & 45,3 \\
& $46-55$ years old & 15 & 9,4 \\
Marital & $55<$ years old & 3 & 1,9 \\
\cline { 2 - 4 } & Total & 159 & 100 \\
\hline & Unmarried & 19 & 11,9
\end{tabular}




\begin{tabular}{llcc}
\hline \multirow{2}{*}{ Status } & Married & 106 & 66,7 \\
& Divorced & 31 & 19,5 \\
& Widower & 3 & 1,9 \\
\cline { 2 - 4 } & Total & 159 & 100 \\
\hline \multirow{3}{*}{ Educational } & Primary Education & 16 & 10,1 \\
Level & Secondary Education & 56 & 35,2 \\
& University Education & 78 & 49,1 \\
& Postgraduate Studies & 9 & 5,7 \\
\cline { 2 - 4 } Economic & Total & 159 & 100 \\
\hline \multirow{2}{*}{ Level } & High & 31 & 19,5 \\
& Middle & 85 & 53,5 \\
& Low & 31 & 19,5 \\
\multirow{2}{*}{ Place of } & Unmployment & 12 & 7,5 \\
\cline { 2 - 4 } Residence & Total & 159 & 100 \\
\hline
\end{tabular}

\section{Results}

Table 2: test distribution of the sample in terms of the characteristics of the sample with the non-parametric test $1 \mathrm{~K}-\mathrm{S}$ Kolmogorov Smirnov

\begin{tabular}{ccc}
\hline Questions & $\begin{array}{c}\text { One-Sample } \\
\text { Kolmogorov - Smirnov Test }\end{array}$ & $\begin{array}{c}\text { Asymp. } \\
\text { Sig. (2-tailed) }\end{array}$ \\
\hline $\mathbf{1}$ &, 207 &, 001 \\
$\mathbf{2}$ &, 236 &, 001 \\
$\mathbf{3}$ &, 209 &, 001 \\
$\mathbf{4}$ &, 186 &, 001 \\
$\mathbf{5}$ &, 226 &, 001 \\
$\mathbf{6}$ &, 214 &, 001 \\
$\mathbf{7}$ &, 251 &, 001 \\
$\mathbf{8}$ &, 203 &, 001 \\
$\mathbf{9}$ &, 194 &, 001 \\
$\mathbf{1 0}$ &, 179 &, 001 \\
\hline
\end{tabular}

The Kolmogorov Smirnov test (table 1, figure 1) for the control of the distribution of the answers of the sample ( $f=159,100 \%$ ) showed values, separately for each question from the ten of the questionnaire with a degree of significance .001 respectively. This means that there is no smooth distribution in the answers to our sample. Then, after checking the reliability and factor analysis, the non-parametric method of statistical analysis $x 2$ will be used. 


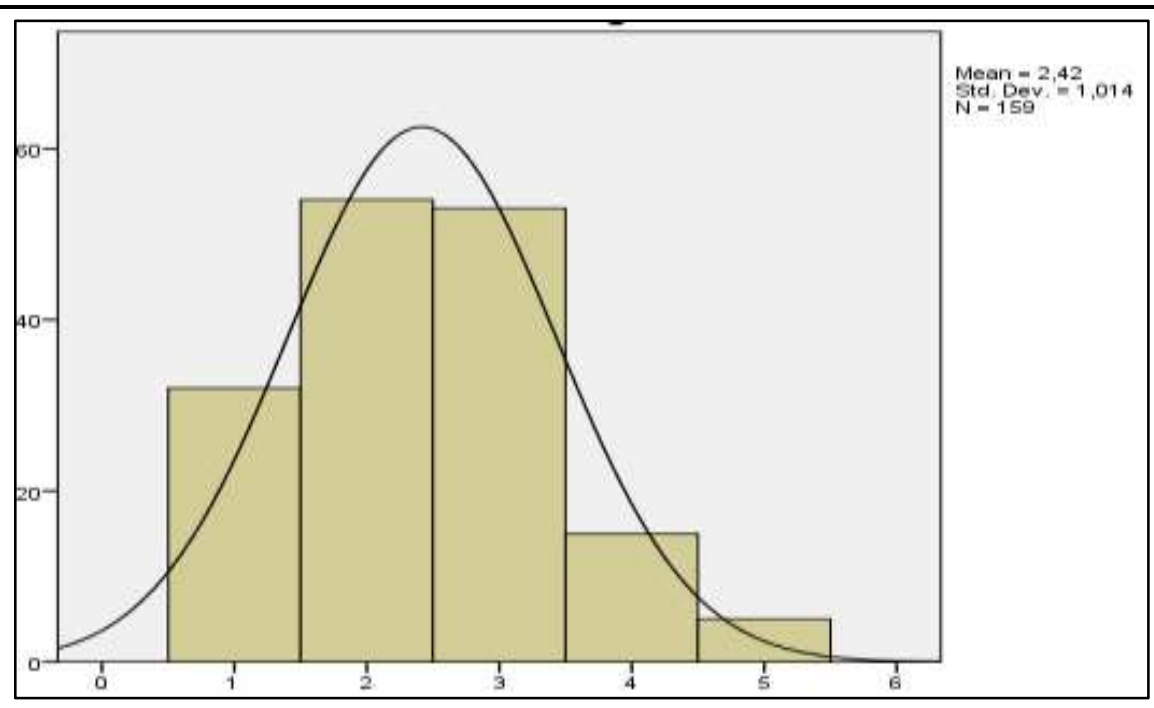

Figure 1: Indicative graphic representation of the distribution of the answers of the sample for the first question

The a-Cronbach reliability for the ten elements of the questionnaire is .840, which shows that the questionnaire has good reliability. Then Guttman's Split half split reliability for the ten elements of the questionnaire is .76, which shows that the scale has good reliability.

Table 3: Rectangular loading matrix for ten elements of the questionnaire and for $(\mathrm{f}=159,100 \%)$

\begin{tabular}{lcccc}
\hline & Factor $\mathbf{1}$ & Factor 2 & Factor 3 & Factor 4 \\
\hline $1^{\text {st }}$ Question &, 788 &, 071 &, 011 &, 037 \\
\hline 2 2nd Question &, 779 &, 287 &,- 062 &,- 200 \\
\hline $3^{\text {rd }}$ Question &, 658 &,- 431 &,- 209 &, 015 \\
\hline $4^{\text {th }}$ Question &, 645 &,- 121 &, 173 &, 122 \\
\hline $5^{\text {th }}$ Question &, 590 &,- 354 &,- 081 &, 166 \\
\hline $6^{\text {th }}$ Question &, 531 &,- 212 &,- 024 &,- 380 \\
\hline $7^{\text {th }}$ Question &,- 069 &, 880 &,- 014 &, 019 \\
\hline $8^{\text {th }}$ Question &,- 031 &,- 130 &, 873 &,- 029 \\
\hline $9^{\text {th }}$ Question &, 040 &, 476 &, 670 &,- 083 \\
\hline $10^{\text {th }}$ Question &, 072 &,- 050 &,- 081 &, 922 \\
\hline
\end{tabular}

An analysis of key factors (Table 3) for the correlations of the six variables was performed. First, four factors were extracted with roots equal to or greater than 1.00. Table 2 shows the charging matrix of rectangular factors for ten elements of the questionnaire and for ( $\mathrm{f}$ $=159,100 \%$ ). The rectangular rotation of the factors gave the structure shown in Table 2 . The first factor (negatively adjacent view / negativity) is responsible for $55 \%$ of the variation, the second factor (positively adjacent view / positive) is responsible for $8 \%$ of variation, the third factor (evidence of success of the inclusion) is responsible for $16 \%$ of the variance and the fourth factor (uncertainty) is responsible for $8 \%$ of the variance. 
Table 4: Descriptive statistics for both the distribution of occurrence and relative frequencies as well as the mean and standard deviation for the ten questions of the questionnaire for $f=159,100 \%$

\begin{tabular}{|c|c|c|c|c|c|c|c|c|c|c|c|c|c|c|c|c|c|c|c|c|}
\hline \multirow[t]{2}{*}{ Skor } & \multicolumn{2}{|c|}{$\begin{array}{c}1^{t} \\
\text { question }\end{array}$} & \multicolumn{2}{|c|}{$\begin{array}{c}2^{\text {nd }} \\
\text { question }\end{array}$} & \multicolumn{2}{|c|}{$\begin{array}{c}3^{\text {rt }} \\
\text { question }\end{array}$} & \multicolumn{2}{|c|}{$\begin{array}{c}4^{\text {th }} \\
\text { question }\end{array}$} & \multicolumn{2}{|c|}{$\begin{array}{c}5^{\text {th }} \\
\text { question }\end{array}$} & \multicolumn{2}{|c|}{$\begin{array}{c}6 t \\
\text { question }\end{array}$} & \multicolumn{2}{|c|}{$\begin{array}{c}\text { 7th } \\
\text { guestion }\end{array}$} & \multicolumn{2}{|c|}{$\begin{array}{c}\rho^{\text {hi }} \\
\text { question }\end{array}$} & \multicolumn{2}{|c|}{$\begin{array}{c}9^{\text {ght }} \\
\text { question }\end{array}$} & \multicolumn{2}{|c|}{$\begin{array}{c}10^{\text {th }} \\
\text { question }\end{array}$} \\
\hline & $\mathrm{f}$ & $\%$ & $\mathrm{f}$ & $\%$ & $\mathrm{f}$ & $\%$ & $\mathrm{f}$ & $\%$ & $\mathrm{f}$ & $\%$ & $\mathrm{f}$ & $\%$ & $\mathrm{f}$ & $\%$ & $\mathrm{f}$ & $\%$ & $\mathrm{f}$ & $\%$ & $\mathrm{f}$ & $\%$ \\
\hline 1 & 32 & 20,1 & 18 & 11,3 & 38 & 23,9 & 36 & 22,6 & & & & & & & & & 44 & 27,7 & 42 & 26,4 \\
\hline 2 & 54 & 34,0 & 60 & 37,7 & 52 & 32,7 & 46 & 28,9 & 5 & 3,1 & 5 & 3,1 & 20 & 12,6 & 6 & 3,8 & 47 & 29,6 & 43 & 27,0 \\
\hline 3 & 53 & 33,3 & 49 & 30,8 & 41 & 25,8 & 47 & 29,6 & 28 & 17,6 & 44 & 27,7 & 66 & 41,5 & 42 & 26,4 & 40 & 25,2 & 40 & 25,2 \\
\hline 4 & 15 & 9,4 & 23 & 14,5 & 21 & 13,2 & 23 & 14,5 & 74 & 46,5 & 55 & 34,6 & 57 & 35,8 & 53 & 33,3 & 28 & 17,6 & 29 & 18,2 \\
\hline 5 & 5 & 3,1 & 9 & 5,7 & 7 & 4,4 & 7 & 4,4 & 52 & 32,7 & 55 & 34,6 & 16 & 10,1 & 58 & 36,5 & & & 5 & 3,1 \\
\hline Total & 159 & 100 & 159 & 100 & 159 & 100 & 159 & 100 & 159 & 100 & 159 & 100 & 159 & 100 & 159 & 100 & 159 & 100 & 159 & 100 \\
\hline IEAN & & 12 & & & & & & & & & & 01 & & 43 & & 03 & & & & 15 \\
\hline S.Der. & & & & 04 & & 2 & & & & 9 & & 6 & & 3 & 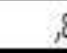 & 8 & & & & 5 \\
\hline
\end{tabular}

We then used $x 2$ tests (Kruskal Wallis) to assess whether two or more samples, which consist of frequency data, differ significantly from each other (Table 5).

For the sex of the respondents it was found that: for the first factor there are no differences between men and women $(\chi 2=2,12, \mathrm{df}=1, \mathrm{p}=, 137)$, while for the second factor $(\chi 2=41,73, \mathrm{df}=1, \mathrm{p}=, 001)$, the third factor $(\chi 2=25,89, \mathrm{df}=1, \mathrm{p}=, 001)$ and the fourth factor $(\chi 2=4,72, \mathrm{df}=1, \mathrm{p}=, 030)$ were found to have differences between men and women.

For the age of the respondents it was found that: for the first factor $(\chi 2=134,14, \mathrm{df}$ $=4, \mathrm{p}=, 001)$, for the second factor $(\chi 2=60,26, \mathrm{df}=4, \mathrm{p}=, 001)$, for the third factor $(\chi 2=$ $38,67, \mathrm{df}=4, \mathrm{p}=, 001)$ and the fourth factor $(\chi 2=27,43, \mathrm{df}=4, \mathrm{p}=, 001)$ there are significant differences between the age groups.

For the educational level of the respondents it was found that: for the first factor $(\chi 2=45,22, \mathrm{df}=3, \mathrm{p}=, 001)$, for the second factor $(\chi 2=33,22, \mathrm{df}=3, \mathrm{p}=, 001)$, for the third factor $(x 2=27.96, d f=3, p=, 001)$ and the fourth factor $(x 2=33.80, d f=3, p=, 009)$ there are significant differences between the groups that determine educational level.

For the financial level of the respondents it was found that: for the first factor $(\chi 2$ $=64,65, \mathrm{df}=3, \mathrm{p}=, 001)$, for the second factor $(\chi 2=42,37, \mathrm{df}=3, \mathrm{p}=, 001)$, for the third factor $(\chi 2=44,39, \mathrm{df}=3, \mathrm{p}=, 001)$ and the fourth factor $(\chi 2=17.66, \mathrm{df}=3, \mathrm{p}=, 009)$ there are significant differences between the groups that determine economic level.

For the area, the place of residence of the respondents, it was found that: for the first factor $(\chi 2=26,20, d f=1, p=, 001)$ there are significant differences, while for the second factor $(\chi 2=1,71, d f=1, p=, 190)$, for the third factor $(\chi 2=1,95, d f=1, p=162)$ and the fourth factor $(\chi 2=, 01, \mathrm{df}=1, \mathrm{p}=, 911)$ there are not significant differences between the regions. 
Table 5: $x 2$ control (Kruskal Wallis) to assess whether two or more samples (gender, age, educational level, marital status, economic level and place of residence) consisting of frequency data differ significantly from each other for $\mathrm{f}=159,100 \%$

\begin{tabular}{|c|c|c|c|c|c|}
\hline & & $1^{\text {st }}$ Factor & $2^{\text {nd }}$ Factor & $3^{\text {rd }}$ Factor & $4^{\text {th }}$ Factor \\
\hline \multirow{3}{*}{ Sex } & $\mathrm{x}^{2}$ & 2,21 & 41,73 & 25,89 & 4,72 \\
\hline & df & 1 & 1 & 1 & 1 \\
\hline & $p$ & ,137 & ,001 & ,001 & ,030 \\
\hline \multirow{3}{*}{ Age } & $x^{2}$ & 134,14 & 60,26 & 38,67 & 27,43 \\
\hline & df & 4 & 4 & 4 & 4 \\
\hline & $p$ & ,001 & ,001 & ,001 & ,001 \\
\hline \multirow{3}{*}{$\begin{array}{l}\text { Marital } \\
\text { Status }\end{array}$} & $x^{2}$ & 11,66 & 33,80 & 75,68 & 11,60 \\
\hline & df & 3 & 3 & 3 & 3 \\
\hline & $p$ & ,009 & ,001 & ,001 & ,009 \\
\hline \multirow{3}{*}{$\begin{array}{l}\text { Education } \\
\text { Level }\end{array}$} & $x^{2}$ & 45,22 & 33,22 & 27,96 & 33,80 \\
\hline & $\mathrm{df}$ & 3 & 3 & 3 & 3 \\
\hline & $p$ & ,001 & ,001 & ,001 & ,001 \\
\hline \multirow{3}{*}{$\begin{array}{l}\text { Economic } \\
\text { Level }\end{array}$} & $x^{2}$ & 64,65 & 42,37 & 44,39 & 17,66 \\
\hline & $\mathrm{df}$ & 3 & 3 & 3 & 3 \\
\hline & $p$ & ,001 & ,001 & ,001 & ,001 \\
\hline \multirow{3}{*}{$\begin{array}{l}\text { Place of } \\
\text { Residence }\end{array}$} & $x^{2}$ & 26,20 & 1,71 & 1,95 & 01 \\
\hline & df & 1 & 1 & 1 & 1 \\
\hline & $p$ & ,001 & 190 & ,162 & ,911 \\
\hline
\end{tabular}

\section{Discussion}

The inclusion of children with ASD in the general school classroom is now a reality. All persons involved in the educational process are invited to accept the event and to act in their entirety to achieve the smooth running of the school. By conducting our research, we wanted to see the views expressed by Greek parents and in particular the residents of the prefectures of Arta and Preveza for the inclusion of children with ASD in the classroom where their child studies, but also and the factors that influence their decisions. The questions of our research tool as a whole have been thoroughly tested and the results emphasize the following key points:

Overall, respondents responded positively to the inclusion of children with ASD in their child's classroom in general school. More specifically, the majority of surveyed parents of TE children are not negative about attending a child with ASD in their child's classroom, nor do they feel particularly anxiety and caution. The present study generally supports previous findings on the views of parents on the inclusion of children with autism in the general classroom, which have taken place in other countries where integration and co-education have been applied for more years than in Greece (Yasutake \& Lerner, 1997, Stoiber et al., 1998). In all of the reported studies, parents of TE children appear to have a positive attitude toward integration and co-education.

According to the surveyed parents, the co-education programs contribute greatly to the good interpersonal communication of children with ASD with TE students and 
therefore to their socialization and integration into society. According to Mamah et al., (2011), the method of co-education helps children with disabilities in terms of their social self-improvement, while a study by Katz \& Mirenda, (2002), showed that the establishment of friendly relations with peers without disabilities is a key factor in the development of students' social skills with multiple disabilities. At the same time, except for the social benefits of inclusion for students with ASD, parents of TE children of our research consider in the vast majority that establishing friendly relations between their children and children with ASD will benefit them and will not stigmatize or marginalize them. The social benefits of inclusion for children with and without educational needs have been demonstrated in previous relevant studies (Narumanchi \& Bhargava, 2011; De Boer et al, 2012; Hilbert, 2014; Soulis et al, 2016; Vlachou et al, 2016).

Our research also shows that Greek parents do not believe that their children of typical education will be negatively affected by the inclusion in educational level and do not consider that the classroom teacher will have his attention more focused on students with ASD. On the contrary, they are positive about inclusion, believing that the teacher will be objective towards all students and say that their children's academic education will not be affected. A review of Kalambouka et al (2007) confirms these findings, showing that the inclusion of students with special educational needs in general schools did not have a negative impact on the learning of their typically developing peers. Peck et al. $(2004,141)$ found that $78 \%$ of parents did not believe that inclusion affects their children academically in a positive or in a negative way. Furthermore, in our research, the majority of participating parents have no problem their child attending the same class with a child with ASD, unless its school performance is affected. However, in studies by Kalyva, Georgiadi, and Tsakiris (2007), Stahmer et al. (2003) views of parents of children of typical education show that students of typical education will not only not reduce their academic performance, but also instead will benefit academically from inclusion as more material and teaching aids will be used.

Furthermore, our research examined the view of Greek parents on the configuration of the classroom space and the answers emphasized the importance of this factor so that the child with ASD is facilitated by the whole process and their own child to be in a comfortable class. The results of this research are also confirmed by the case study of Coffey \& Obringer (2004), which refer to the position that parents take in favor of the appropriate configuration of the space. In particular, it was pointed out that the atmosphere in a smaller one compared to other schools contributed to the good performance of the children of both groups (Coffey \&, Obringer, 2004).

Then, the four factors, created by the ten questions, intersected with the demographic characteristics to show the effects between them. The results showed significant differences between the groups that determine educational level, marital status, economic level and age regarding to all the factors.

Regarding age, the results of our research show that the age of the participants affected their responses, with the younger ones being more positive and open to the 
inclusion of people with ASD in their child's general school class compared to older ones. Younger parents of children of TE express a more positive view of inclusion, show less anxiety and caution towards children with ASD and have no particular problem with having a child with ASD in their child's classroom. This result is consistent with the results of a previous study (De Boer, \& Munde, 2014), in which it was found that the younger the parents are, the more positive they appear towards integration. In contrast, a Hamour \& Muhaidat (2013) study did not appear to have statistically significant differences between different age groups of parents, while Sosu, \& Rydzewska (2017) observed that the older the parents are, the more positive the view had for inclusion.

The educational level of the participants showed that it plays a special role in their answers. The results of the research showed that those participants who had a master's degree or were graduates of higher education, expressed more positive views about the inclusion of children with ASD in their child's class in the general school. More specifically, those who had received higher education were more receptive to inclusion, did not believe in the negative impact of inclusion programs on their child's teaching, and at the same time disagreed with the stigma and marginalization of their child being friend with his classmate with ASD. These findings are confirmed by research by AbuHamour \& Muhaidat (2014), Aydın \& Yamac (2014), Sosu, \& Rydzewska (2017), who observed that the high educational level of the parents was associated with positive views towards integration. Also, another research of Hamour \& Muhaidat (2013), shows parents with higher education more positive towards the integration of students with learning difficulties in general education. Other researchers (De Boer et al, 2012; De Boer $\&$ Munde, 2014) have shown that the educational level of parents does not differentiate their attitudes.

In terms of demographic features marital status and economic level, appeared to influence participants' responses. Married parents and those in better financial condition expressed more positive views about the inclusion of children with autism in the general school. Also, in terms of gender and place of residence, they did not appear to affect all respondents' responses without showing statistically significant differences.

\section{Conclusions}

In conclusion, our research shows that Greek parents in the regions of Arta and Preveza are positive, encouraging the existence of a child with ASD in their child's classroom. The present study generally supports previous findings on parental views on the inclusion of children with autism in the general classroom and considers important some factors that play a key role in parental responses. The results of the present study clearly show that the factors age, educational level, economic level and marital status of the participants have a decisive influence on their responses, and we believe that future research should also be taken into account. 
In general, we would say that the present study expresses the views of Greek parents, makes a brief reference to the factors that may play a role in parents' responses to the inclusion of a student with ASD in their child's classroom and prompts other researchers to continue and explore other factors.

\section{Restrictions and Suggestions for Further Research}

Although the sample is quite representative, it concerns only limited areas of Greek territory, and more specifically only the cities of Arta and Preveza, and therefore makes it difficult to generalize the results to the general population. Another limitation is that the present survey for inclusion did not examine any parameters except for the specific socio-demographic characteristics of the participants, which may affect the views of the respondents. As a last resort we can add the fact that not all parents surveyed had a child with ASD in their child's classroom.

As for some suggestions that could be made, we could say that future research can include and examine the views of all stakeholders affected by inclusion, such as children with typical education, autistic children, special and general education teachers and parents of children of formal and special education. It is also useful to find a larger sample in order to get participants to provide us with rich information on the issue that concerns us in order to have more secure conclusions in the future and generalizability to the general population. It is also important in future research the samples consist of parents who actually have a child with ASD in their child's classroom as their answers will be based more on the reality they are experiencing and not on hypothetical situations. Last but not least, another assumption of the research concerns the fact that we accept as honest the answers given by the teachers, which gave us some degree of validity of the present research.

\section{Abbreviations}

ASD: Autistic Spectrum Disorder

TE: Typical Education (Children)

\section{References}

Abu-Hamour, B., \& Muhaidat, M. (2014). Parents' attitudes towards inclusion of students with autism in Jordan. International Journal of Inclusive Education. 18:6, pp. 567-579. DOI: $10.1080 / 13603116.2013 .802026$.

Aydin, A. \& Yamac, A. (2014). The relations between the acceptance and childrearing attitudes of parents of children with mental disabilities. Eurasian Journal of Educational Research. 54, pp. 79-98. 
Coffey, K. M, Obringer, S. J. (2004). A Case Study on Autism: School Accommodations and Inclusive Settings, ProQuest Information and Learning Company.

De Boer, A., \& Munde, V. (2014). Parental Attitudes Toward the Inclusion of Children with Profound Intellectual and Multiple Disabilities in General Primary Education in the Netherlands. European Journal of Special Needs Education. 49:3, pp. 179- 187.

De Boer, A., Piil, S. J., Post, W., Minnaert, A. (2012). Which variables relate to the attitudes of teachers, parents and peers towards students with special educational needs in regular education? Educational Studies. 38:4, pp. 433-448.

Gallagher, P. A., J. H. Floyd, A. M. Stafford, T. A. Taber, S. A. Brozovic, and P. A. Alberto (2000). Inclusion of students with moderate or severe disabilities in education and community settings: Perspectives from parents and siblings. Education and Training in Mental Retardation and Developmental Disabilities 35, no. 2: 135-47.

Grabrucker, A. M. (2013). Environmental factors in autism. Frontiers in Psychiatry, 3, 118. Grandin, T. \& Scariano, M. M. (1995). The learning style of people with autism: An autobiography. In K. Quill (Ed.), Teaching children with autism: Strategies to enhance communication and socialization, (pp. 33-52). New York: Delmar.

Hamour B. \& Muhaidat M. (2013). Parents attitudes towards inclusion of students with autism in Jordan. International journal of inclusive education 2014 vol 18, no 6, 567 579

Heward, W. L. (2011). Children with special needs. An introduction to special education. Davazoglou, A., Kokinos, K. (Ed.). Translation: Iymperopoulou, H. Athens: Topos.

Hilbert, D. (2014). Perceptions of Parents of Young Children with and without Disabilities Attending Inclusive Preschool Programs. Journal of Education and Learning. 3:4.

Kakouros, E., \& Maniadaki, K. (2006). Child and Adolescent Psychopathology: A Developmental Approach. Athens: Gutenberg.

Kalambouka, A, Farrell, P, Dyson, A, \& Kaplan, I. (2007). The impact of placing pupils with special educational needs in mainstream schools on the achievement of their peers, Educational Research, 49:4, pp. 365-382, DOI: 10.1080/00131880701717222

Kalyva, E. (2005). Autism: Educational and Therapeutic Approaches. Papazisis Publications.

Katz, J. \& Mirenda, P. (2002). Including students with developmental disabilities in general education classrooms: educational. International Journal of Special Education, 17, (2), 14-24

Lampi, K. M., Lehtonen, L., Tran, P. L., Suominen, A., Lehti, V., Banerjee, P. N., \& Sourander, A. (2012). Risk of autism spectrum disorders in low birth weight and small for gestational age infants. The Journal of Pediatrics, 161(5), 830-836.

Landrigan, D. J. (2010). What causes autism? Exploring the environmental contribution. US. National library of Medicine National institutes Health. 22(2)

Mamah, V., Deku P., Darling, S. \& Avoke, S. (2011). University teacher's perception of inclusion of visually impaired in Chanaian Universities. International Journal of Special Education, 26 (1), 70- 79. 
Mavropoulou, S. (2008). Teaching applications for the inclusion of people with autism in the general school and workplace. Volos: University of Thessaly.

Narumanchi, A., \& Bhargava, S. (2011). Perceptions of Typical Children towards Inclusive Education. Disability, CBR and Inclusive Development. 22:1, DOI 10.5463/ DCID.v22i1.10.

Pardo, C. A., Vargas, D. L., \& Zimmerman, A. W. (2005). Immunity, neuroglia and neuroinflammation in autism. International Review of Psychiatry, 17(6), 485-495.

Peck, Charles, Debbie Staub, Chrysan Gallucci, and Ilene Schwartz (2004). Parent Perception of the Impacts of Inclusion on Their Nondisabled Child. Research and Practice for Persons with Severe Disabilities, 29 (2): 135-143. doi:10.2511/rpsd.29.2.135

Sosu, E. M., \& Rydzewska, E. (2017): “Are all beliefs equal?" investigating the nature and determinants of parental attitudinal beliefs towards educational inclusion. Educational Studies. 43:5. pp. 516-532. DOI: 10.1080/03055698.2017.1312286 Recovered 4th April 2018, from https://www.tandfonline.com/doi/full/10.1080/03055698.2017.1312286

Soulis, S. G., Georgiou, A., Dimoula, K., \& Rapti, D. (2016). Surveying inclusion in Greece: empirical research in 2683 primary school students. International Journal of Inclusive Education. 20:7, pp. 770-783. DOI: 10.1080/13603116.2015.1111447

Stahmer, A., Carter, C., Mary Baker, M., \& Miwa, K. (2003). Parent Perspectives on Their Toddlers' Development: Comparison of Regular and Inclusion Childcare. Early Child Development and Care 173 (5): 477-488. doi:10.1080/0300443032000088267

Stoiber K., Gettinger M., Goedz D. (1998). Exploring factors influencing parents and early childhood practitioners' beliefs about inclusion. Early childhood research quarterly, $13,107-124$

Syropoulou-Deli, X. \& Kassimos, D. C. (2013). Communication and education of people with Diffuse Developmental Disorders / Autism. Thessaloniki: University of Macedonia ed.

Tafa E., Manolitsis G. (2003). Attitudes of Greek parents of typically developing kindergarten children towards inclusive education. European journal of special needs education 2003 vol 18, no 2, 155 - 171

Vlachou, A., Karadimou, S., \& Koutsogeorgou, E. (2016). Exploring the views and beliefs of parents of typically developing children about inclusion and inclusive education. Educational Research. 58:4. pp. 384-399.

$\mathrm{Xu}$, Y. \& Filler, J. (2008). Facilitating Family Involvement and Support for Inclusive Education, The School Community Journal, 18 (2), 53-72.

Yasutake D. \& Lerner J. (1997). Parents perceptions of inclusion: a survey of parents of special education and non- special education students, Learning disabilities: $A$ Multidisciplinary Journal, 8, 117-120. 
Zaragas Harilaos, Sarris Dimitrios, Exarchou Evangelia,

Papadimitropoulou Panagoula, Exarchos Konstantinos, Maglara Vasiliki

VIEWS OF PARENTS WITH TYPICAL EDUCATION CHILDREN ABOUT

INCLUSION OF CHILDREN WITH AUTISM IN GENERAL SCHOOL

Creative Commons licensing terms

Authors will retain the copyright of their published articles agreeing that a Creative Commons Attribution 4.0 International License (CC BY 4.0) terms will be applied to their work. Under the terms of this license, no permission is required from the author(s) or publisher for members of the community to copy, distribute, transmit or adapt the article content, providing a proper, prominent and unambiguous attribution to the authors in a manner that makes clear that the materials are being reused under permission of a Creative Commons License. Views, opinions and conclusions expressed in this research article are views, opinions and conclusions of the author(s). Open Access Publishing Group and European Journal of Special Education Research shal not be responsible or answerable for any loss, damage or liability caused in relation to/arising out of conflict of interests, copyright violations and inappropriate or inaccurate use of any kind content related or integrated on the research work. All the published works are meeting the Open Access Publishing requirements and can be freely accessed, shared, modified, distributed and used in educational, commercial and non-commercial purposes under a Creative Commons Attribution 4.0 International License (CC BY 4.0). 